\title{
Magnetostructural phase transitions and magnetocaloric effects in as-cast $\mathrm{Mn}_{1-\mathrm{x}} \mathrm{Al}_{\mathrm{x}} \mathrm{CoGe}$ compounds
}

$\underline{\text { Anil Aryal }}{ }^{\mathrm{a}, *}$, Abdiel Quetz $^{\mathrm{a}}$, Sudip Pandey ${ }^{\mathrm{a}}$, Tapas Samanta ${ }^{\mathrm{c}}$, Igor Dubenko ${ }^{\mathrm{a}}$, Margaret Hill ${ }^{\mathrm{b}}$, Dipanjan Mazumdar ${ }^{\mathrm{a}}$, Shane Stadler ${ }^{\mathrm{c}}$, and Naushad Ali ${ }^{\mathrm{a}}$

\begin{abstract}
:
The structural and magnetic properties of as-cast $\mathrm{Mn}_{1-\mathrm{x}} \mathrm{Al}_{\mathrm{x}} \mathrm{CoGe}(0 \leq \mathrm{x} \leq 0.05)$ have been studied by X-ray diffraction, differential scanning calorimetry, and magnetization measurements. The partial substitution of $\mathrm{Al}$ for $\mathrm{Mn}$ in $\mathrm{Mn}_{1-\mathrm{x}} \mathrm{Al}_{\mathrm{x}} \mathrm{CoGe}$ results in a decrease in the martensitic transition temperature $T_{M}$. For the concentration range $0 \leq x \leq 0.01, T_{M}$ was found to coincide with ferromagnetic transition temperature $\left(\mathrm{T}_{\mathrm{C}}\right)$ resulting in a first-order magnetostructural transition (MST). A further increase in aluminum concentration resulted in a splitting of the phase transition temperatures, which included a drastic decrease in the martensitic temperature. The compounds with $x>0.02$ showed a single transition at $T_{C}$. The maximum values of the magnetic entropy changes $\left(-\Delta \mathrm{S}_{\mathrm{M}}\right)$ were $\sim 18 \mathrm{~J} / \mathrm{kgK}, 12 \mathrm{~J} / \mathrm{kgK}$, and $7 \mathrm{~J} / \mathrm{kgK}$ for $\Delta \mathrm{H}=5 \mathrm{~T}$ at $313 \mathrm{~K}$ $(\mathrm{x}=0.00), 286 \mathrm{~K}(\mathrm{x}=0.01)$, and $220 \mathrm{~K}(\mathrm{x}=0.02)$, respectively. The maximum value of the relative cooling power $(\mathrm{RCP})$ was found to be $303 \mathrm{~J} / \mathrm{kg}$ for $\mathrm{x}=0.01$ at $\mathrm{T}=286 \mathrm{~K}$ for $\Delta \mathrm{H}=5 \mathrm{~T}$. It
\end{abstract}


has been established that as-cast samples of this system show large value of MCE near room temperature making this system a promising material for magnetic cooling technologies.

\section{Introduction}

The magnetocaloric effect (MCE) refers to an adiabatic temperature change $\left(\Delta \mathrm{T}_{\mathrm{A}}\right)$ or isothermal magnetic entropy change $\left(\Delta \mathrm{S}_{\mathrm{M}}\right)$ in a magnetic material, induced by an applied magnetic field. Near room temperature MCE has been a subject of interest for decades because of its potential application in magnetic refrigeration, which is a possible eco-friendly and energy efficient cooling technology alternative to the conventional vapor cycle refrigeration $[1,2]$. The largest MCEs have been observed in several materials such as $\mathrm{Gd}_{5} \mathrm{Si}_{2} \mathrm{Ge}_{2}$ [3], $\mathrm{MnFe}(\mathrm{P}, \mathrm{As})$ [4], $\mathrm{LaFe}_{13-\mathrm{x}} \mathrm{Si}_{\mathrm{x}}[5], \mathrm{NiMn}(\mathrm{Ga}, \mathrm{Sb}, \mathrm{In})$ based Heusler alloys [6], and $\mathrm{MnAs}_{1-\mathrm{x}} \mathrm{Sb}_{\mathrm{x}}$ [7], which show firstorder simultaneous transitions in the magnetic and crystal structures, i.e., magnetostructural transitions (MSTs). The mechanisms responsible for the MSTs are not completely understood, and hence the exploration and study of the new materials that exhibit MSTs is important for applications and fundamental physics.

MnCoGe belongs to a wider class of materials with composition MM'X, where M, M' are $3 d$ transition metals and $\mathrm{X}$ is $\mathrm{Si}$ or Ge. Stoichiometric MnCoGe has a ferromagnetic (FM) phase below the Curie temperature $\left(\mathrm{T}_{\mathrm{C}} \sim 345 \mathrm{~K}\right)$. It transforms to a high-temperature, hexagonal $\mathrm{Ni}_{2}$ In-type structure from a low-temperature orthorhombic TiNiSi-type structure at $\mathrm{T}_{\mathrm{M}} \sim 650 \mathrm{~K}$ in the paramagnetic $(\mathrm{PM})$ region [8]. If the structural transition temperature $\left(\mathrm{T}_{\mathrm{M}}\right)$ is tuned to coincide with $\mathrm{T}_{\mathrm{C}}$, a magnetostructural phase transition (MST) with large change in magnetization can be expected, which enhances the potential for large MCE. It has been reported that changes in stoichiometry, chemical composition, or application of external pressure can result in the 
coincidence of the magnetic and structural transitions, therefore may increase the magnetic entropy change to show a large MCE [9-16]. The effects of substituting Al for Co or Ge in MnCoGe have been reported in Refs. [17, 18]. Recently, Si, et. al. [19] showed the parent MnCoGe compound is in the hexagonal phase at room temperature and the crystal structure changes to orthorhombic by substituting $\mathrm{Al}$ in $\mathrm{Mn}$ sites. Various groups working in this system previously have reported different $T_{M}$ values ranging from $420 \mathrm{~K}$ to $650 \mathrm{~K}[8,9,15,20]$. The reason behind such variation in the martensitic temperature is identified as a change in crystallographic order due to composition and heat treatment methods [21]. This seems to indicate that the MnCoGe system is sensitive to the sample synthesis procedure and heat treatment. In this work, we present the results of our study on the partial substitution of $\mathrm{Al}$ for Mn in the $\mathrm{Mn}_{1-\mathrm{x}} \mathrm{Al}_{\mathrm{x}} \mathrm{CoGe}$ system, which exhibits a MST and leads to a large MCE near room temperature.

\section{Experimental Details}

Polycrystalline $\mathrm{Mn}_{1-\mathrm{x}} \mathrm{Al}_{\mathrm{x}} \mathrm{CoGe}$ samples with nominal compositions $0 \leq \mathrm{x} \leq 0.05$ were synthesized by arc-melting high purity elements (99.99\%) in an ultra-high purity argon atmosphere. The samples were turned over and re-melted 4 times to ensure better homogeneity. Mass loss after melting was found to be between $0.03-0.3 \%$ for the compounds with $0.00<\mathrm{x} \leq$ 0.05. For $\mathrm{x}=0.00$, a $0.7 \%$ loss in mass was recorded. Assuming mass loss in Mn only, the samples can be considered slightly off-stoichiometric. As-cast samples were used for all measurements. The crystal structure was studied by powder X-ray diffraction (XRD) using $\mathrm{CuK} \alpha$ radiation at room temperature. The XRD pattern has been indexed for hexagonal and orthorhombic phases. The cell parameters of high temperature (hexagonal phase) have been 
calculated using the refined curves. The magnetic properties of the $\mathrm{Mn}_{1-\mathrm{x}} \mathrm{Al}_{\mathrm{x}} \mathrm{CoGe}$ compounds were measured using a SQUID magnetometer (Quantum Design) in the temperature interval 5 $380 \mathrm{~K}$ in applied magnetic fields up to $5 \mathrm{~T}$. Magnetic measurements were taken following zero field cooled (ZFC) and field cooled (FC)-protocols. Differential scanning calorimetry (DSC) measurements were obtained using a DSC 8000 instrument (with a ramp rate of $30 \mathrm{~K} / \mathrm{min}$ during heating and cooling) in the temperature range 123 - $423 \mathrm{~K}$. Latent heat (L) was estimated from the endothermic peaks of the heat flow curves using $L=\int_{T_{S}}^{T_{f}} \frac{d Q}{d T} d T$, where $\frac{d Q}{d T}$ is the change in heat flow with respect to temperature, and $T_{s}$ and $T_{f}$ are initial and final temperatures of the magnetostructural phase transition on heating.

\section{Results and Discussion}

The room temperature XRD patterns for the as-cast $\mathrm{Mn}_{1-\mathrm{x}} \mathrm{Al}_{\mathrm{x}} \mathrm{CoGe}$ compounds are shown in Fig. 1(a). For $\mathrm{x}=0$, the orthorhombic (TiNiSi-type) and hexagonal $\left(\mathrm{Ni}_{2}\right.$ In-type) phases coexist indicating that the structural transition in this compound occurs near room temperature. At lower Al concentration, $\mathrm{x}=0.01$, the hexagonal $\left(\mathrm{Ni}_{2} \mathrm{In}\right.$-type $)$ structure stabilizes near room temperature with a small trace of orthorhombic phase. With a further increase in Al concentration $(\mathrm{x}=0.02$, $0.03,0.05)$, the compounds crystallize in a single-phase hexagonal $\mathrm{Ni}_{2} \mathrm{In}$-type structure. This indicates that the partial substitution of $\mathrm{Al}$ for $\mathrm{Mn}$ in $\mathrm{Mn}_{1-\mathrm{x}} \mathrm{Al}_{\mathrm{x}} \mathrm{CoGe}$ serves to stabilize the high temperature austenite phase. The above results from XRD are in accordance with the results presented in earlier studies for similar systems [17, 18, 22, and 23] and contrast with results presented in [19].

The Rietveld refinements of the XRD patterns (hexagonal phase) of the representative compounds $(\mathrm{x}=0.01$ and 0.02$)$ are shown in Fig. 1(b) and (c). The calculated values of the 
lattice parameters and corresponding unit cell volumes for various $\mathrm{Al}$ concentrations are shown in Table 1. It is interesting to note that the cell parameters of the $\mathrm{Mn}_{1-\mathrm{x}} \mathrm{Al}_{\mathrm{x}} \mathrm{CoGe}$ compound follow Vegard's law [24] for small Al concentrations. The volumes of the crystal cells and cell parameters were found to increase in the interval $\mathrm{x}=0.00-0.02$, and decrease with larger aluminium concentrations. The increase in the cell parameters was expected due to the larger metallic radius of $\mathrm{Al}(1.432 \AA)$ compared to $\mathrm{Mn}(1.264 \AA)$ [25]. The decrease in crystal cell volume when the $\mathrm{Al}$ concentration $\mathrm{x}>0.02$ is most likely related to the increase in the thermal expansion coefficient with aluminum content. However detailed temperature-dependent XRD studies are required to make strong conclusions concerning the reason of such anomalous behavior.

Fig. 2(a) shows the temperature dependence of the magnetization $M(T)$ of the as-cast $\mathrm{Mn}_{1-\mathrm{x}} \mathrm{Al}_{\mathrm{x}} \mathrm{CoGe}$ compounds with $0 \leq \mathrm{x} \leq 0.05$. The $\mathrm{M}(\mathrm{T})$ curves were measured during heating and cooling cycles from $10 \mathrm{~K}-380 \mathrm{~K}$ in an applied magnetic field of $100 \mathrm{Oe}$. All of the compounds show ferromagnetic order at low temperatures. On increasing temperature, a large drop in magnetization typical for a FM to $\mathrm{PM}$ transition at $\mathrm{T}_{\mathrm{C}}$ was observed. Compounds with $\mathrm{x}$ $=0.00,0.01$, and 0.02 show a thermal hysteresis of $10 \mathrm{~K}, 7 \mathrm{~K}$, and $7 \mathrm{~K}$, respectively, between heating and cooling cycles. The thermal hysteresis in magnetization is a signature of the temperature induced first-order transition, and therefore indicates a first-order structural transformation in these compounds at $\mathrm{T}_{\mathrm{M}}$. For the compounds with $\mathrm{x}=0.00$ and $\mathrm{x}=0.01$, the magnetic transition temperature $\left(\mathrm{T}_{\mathrm{C}}\right)$ and the structural transition temperature $\left(\mathrm{T}_{\mathrm{M}}\right)$ coincide to produce a first-order MST from a FM TiNiSi - type phase to a $\mathrm{PM} \mathrm{Ni}_{2} \mathrm{In}$ - type phase. It has been reported earlier that stoichiometric $\mathrm{MnCoGe}$ has $\mathrm{T}_{\mathrm{C}} \sim 345 \mathrm{~K}<\mathrm{T}_{\mathrm{M}} \sim 650 \mathrm{~K}$ and its magnetic 
properties are extremely sensitive to Mn concentration. Any deviation from stoichiometry shifts $\mathrm{T}_{\mathrm{M}}$ to a lower temperature so that it may coincide with $\mathrm{T}_{\mathrm{C}}$ to form a MST $[15,16]$.

The $0.7 \%$ loss in mass for the compound with $\mathrm{x}=0.00$ (assuming only Mn loss) corresponds to the molar composition $\mathrm{Mn}_{0.98} \mathrm{CoGe}$. Hence, for $\mathrm{x}=0.00$, the observed MST near room temperature can be explained as a result of a small deviation from stoichiometry that lowers $T_{M}$ to coincide with $T_{C}$. The observed hexagonal $\mathrm{Ni}_{2}$ In-type phase in the XRD pattern at room temperature also supports the above argument. For $x=0.02, T_{M}$ falls below $T_{C}$, and the magnetic and structural transitions decouple. The temperature induced structural transition vanishes in compounds with $\mathrm{x}=0.03$ and 0.05 . Only a second order magnetic transition (SOT) from a FM to PM state was observed in these compounds. The values of the transition temperatures calculated from the minimum of $\mathrm{dM} / \mathrm{dT}$ in the magnetization curve during the heating cycle are listed in Table 2. Thus, by partial substitution of $\mathrm{Al}$ for $\mathrm{Mn}$ in $\mathrm{MnCoGe}, \mathrm{T}_{\mathrm{M}}$ linearly decreased from $313 \mathrm{~K}$ to $220 \mathrm{~K}$ and a first-order MST was observed when $\mathrm{T}_{\mathrm{M}}$ and $\mathrm{T}_{\mathrm{C}}$ coincided near room temperature. The first-order MST seen in the $M(T)$ curves for $x=0.00$, 0.01, and 0.02 were further confirmed by DSC measurements (see Fig 2(b)). The values of the transition temperatures, latent heat $(\mathrm{L})$, thermal hysteresis, and total entropy change $\left(-\Delta \mathrm{S}_{\mathrm{T}}\right)$ are given in Table 2.

The field dependence of magnetization $\mathrm{M}(\mathrm{H})$ at $\mathrm{T}=5 \mathrm{~K}$ is shown in inset of Fig 2(a). The $\mathrm{M}(\mathrm{H})$ curves indicate that all of the compounds possess ferromagnetic ordering in the ground state. The saturation magnetization decreases linearly with increasing Al concentration with a large drop for $\mathrm{x}=0.03$ and $\mathrm{x}=0.05$. Hence, it can be concluded that for compounds that undergo a temperature induced structural transition, the structural change has a significant contribution to the increase in the magnetization in the ground state. 
The magnetic entropy change $\left(-\Delta \mathrm{S}_{\mathrm{M}}\right)$ near the transition temperature for field changes up to $5 \mathrm{~T}$ are plotted in Fig. 4 . The $-\Delta \mathrm{S}_{\mathrm{M}}$ values were calculated from the isothermal magnetization curves $\mathrm{M}(\mathrm{H})$ (shown in Fig. 3) using Maxwell's relation, $\Delta \mathrm{S}_{\mathrm{M}}=\int_{0}^{H}\left(\frac{\partial M}{\partial T}\right)_{H} d H[1,2]$. The Maxwell's relation cannot be used to evaluate $\Delta \mathrm{S}_{\mathrm{M}}$ for ideal FOTs. Ideally, the transition is perfectly discontinuous i.e. $\left(\frac{\partial M}{\partial T}\right)_{H}$ does not exist at the transition temperature. However, most materials do not show ideal discontinuities at the FOT. The changes in $\left(\frac{\partial M}{\partial T}\right)_{H}$ are finite and can be calculated experimentally. Therefore, the Maxwell relation can be used to estimate $\Delta \mathrm{S}_{\mathrm{M}}$ at a FOT in these cases [28]. Relatively large magnetic entropy values of $-\Delta \mathrm{S}_{\mathrm{M}}=18 \mathrm{~J} / \mathrm{kgK}$ (at $\mathrm{T}=$ $313 \mathrm{~K}, \Delta \mathrm{H}=5 \mathrm{~T}$ ) and $12 \mathrm{~J} / \mathrm{kgK}($ at $\mathrm{T}=286 \mathrm{~K}, \Delta \mathrm{H}=5 \mathrm{~T}$ ) were obtained for $\mathrm{x}=0.00$ and 0.01 , respectively. For $x=0.02$, the $-\Delta S_{M}$ values corresponding to a first-order structural transition and a SOT were found to be 7 and $3 \mathrm{~J} / \mathrm{kgK}$, respectively. The $-\Delta \mathrm{S}_{\mathrm{M}}$ values of the compounds with higher $\mathrm{Al}$ content $(\mathrm{x}=0.03$ and $\mathrm{x}=0.05)$ near the SOT were 3.5 and $3.2 \mathrm{~J} / \mathrm{kgK}$, respectively. The above results show that, by a partial substitution of $\mathrm{Mn}$ by $\mathrm{Al}$, the magnetic and structure transition temperatures can be tuned to coincide, resulting in an increase in the magnetization and, finally, resulting in a large $-\Delta S_{M}$. The observed values of $-\Delta S_{M}$ are larger than or comparable with other well-known giant MCE materials such as $\mathrm{Gd}_{5} \mathrm{Si}_{2} \mathrm{Ge}_{2}, \mathrm{MnCoGeB}_{0.01}, \mathrm{Mn}_{1-\mathrm{x}} \mathrm{Cr}_{\mathrm{x}} \mathrm{CoGe}$ (with $\mathrm{x}=0.18$ and 0.25), $\mathrm{MnFeP}_{0.45} \mathrm{As}_{0.55}$ and $\mathrm{La}_{0.70} \mathrm{Ca}_{0.30-\mathrm{x}} \mathrm{Sr}_{\mathrm{x}} \mathrm{MnO}_{3}: \mathrm{Ag}_{0.10}$ manganites [3, 4, 10, $11,26]$. The values of $-\Delta \mathrm{S}_{\mathrm{M}}$ obtained are larger than those of the $\mathrm{Mn}_{1-\mathrm{x}} \mathrm{Al}_{\mathrm{x}} \mathrm{CoGe}$ (heat treated and quenched samples, $\Delta \mathrm{H}=5 \mathrm{~T}$ ) [19] which shows a better enhancement of magnetocaloric properties in this system. 
The relative cooling power (RCP) is an important parameter that estimates the usefulness of a material as a magnetic refrigerant, and can be used to compare different materials. The RCP is a measure of amount of heat transferred between the hot and cold reservoirs in an ideal refrigeration cycle and is defined as: $\mathrm{RCP}=-\Delta \mathrm{S}_{\mathrm{M}}(\max ) \times \Delta \mathrm{T}_{\mathrm{FWHM}}$, where $\Delta \mathrm{T}_{\mathrm{FWHM}}$ is the fullwidth-at-half-maximum of the $-\Delta \mathrm{S}_{\mathrm{M}}$ curve [27]. Large values of the $\mathrm{RCP}=250$ and $303 \mathrm{~J} / \mathrm{kg}$ with $\Delta \mathrm{H}=5 \mathrm{~T}$ were found for the compounds with $\mathrm{x}=0.00$ and 0.01 (those show a MST). For $\mathrm{x}=$ $0.03, \mathrm{RCP}=252 \mathrm{~J} / \mathrm{kg}$. The experimental results are summarized in Table 2 .

A concentration dependent phase diagram has been constructed (Fig.5) using the DSC and magnetization data (Table 2). Substituting $\mathrm{Al}$ for Mn leads to a linear decrease in $\mathrm{T}_{\mathrm{M}}$ from $313 \mathrm{~K}$ to $220 \mathrm{~K}$. For the concentration range $0 \leq \mathrm{x} \leq 0.01, \mathrm{~T}_{\mathrm{M}}$ coincides with $\mathrm{T}_{\mathrm{C}}$ to form a firstorder MST from a FM orthorhombic (TiNiSi-type) structure to a PM hexagonal ( $\mathrm{Ni}_{2} \mathrm{In}$-type) structure close to room temperature. For $0.01<\mathrm{x} \leq 0.02, \mathrm{~T}_{\mathrm{M}}$ is below $\mathrm{T}_{\mathrm{C}}$, and the magnetic and structural transitions decouple. These compounds undergo structural transitions from an orthorhombic (TiNiSi-type) to hexagonal $\left(\mathrm{Ni}_{2} \mathrm{In}\right.$-type) structure in the FM state, followed by a magnetic transition from FM to PM state with hexagonal structure. The compounds with $\mathrm{x}>$ 0.02 stabilize in a hexagonal ( $\mathrm{Ni}_{2}$ In-type) structure without a detectable martensitic transformation below $\mathrm{T}_{\mathrm{C}}$, and undergo magnetic transitions from a FM to a PM state.

\section{Conclusions}

The magnetostructural phase transitions and magnetic entropy changes in as-cast $\mathrm{Mn}_{1-}$ ${ }_{x} \mathrm{Al}_{\mathrm{x}} \mathrm{CoGe}$ compounds have been studied. Through the partial substitution of $\mathrm{Al}$ for $\mathrm{Mn}$ the martensitic transformation temperature decreased and, as a result, a first-order MST formed for 0 $\leq \mathrm{x} \leq 0.01$. For $0.01<\mathrm{x} \leq 0.02, \mathrm{~T}_{\mathrm{M}}$ is below $\mathrm{T}_{\mathrm{C}}$ and the magnetic and structure transitions 
separate. Compounds with $\mathrm{x}>0.02$ form a $\mathrm{Ni}_{2} \mathrm{In}$-type austenite phase with no distinct martensitic transformation below $\mathrm{T}_{\mathrm{C}}$. Large values of $-\Delta \mathrm{S}_{\mathrm{M}}$ and $\mathrm{RCP}$ corresponding to first-order MSTs and SOTs were observed near room temperature. Thus, large values of the magnetic entropy change, RCP, small thermal hysteresis, and non-toxic and less-expensive constituent elements makes this system a promising material for room-temperature magnetic cooling technologies.

Acknowledgements: This work was supported by the U.S. Department of Energy (DOE), Office of Science, Basic Energy Sciences (BES) under Award No. DE-FG02-06ER46291 (SIU) and DE-FG02-13ER46946 (LSU).

\section{References:}

[1] K. A. Gschneidner Jr, V. K. Pecharsky, and A. O. Tsokol Rep. Prog. Phys. 68, 1479 (2005)

[2] A. M. Tishin and Y. I. Spichkin, The Magnetocaloric Effect and its Applications Great Britain Institute of Physics (2003)

[3] V. K. Pecharsky and K. A. Gschneidner Jr., Phys. Rev. Lett. 78, 4494 (1997)

[4] O. Tegus, E. Bruck, K. H. J. Buschow and F. R. de Boer, Nature 415, 150 (2002)

[5] A. Fujita, S. Fujieda, Y. Hasegawa and K. Fukamichi, Phys. Rev. B 67, 104416 (2003)

[6] I. Dubenko, M. Khan, A. K. Pathak, B. R. Gautam, S. Stadler and N. Ali, J. Magn. Magn. Mater. 321, 754 (2009)

[7] H. Wada and Y. Tanabe, Appl. Phys. Lett. 79, 3302 (2001)

[8] T. Kanomata, H. Ishigaki, T. Suzuki, H. Yoshida, S. Abe, T. Kaneko, J. Magn. Magn. Mater., 131, 140 (1995) 
[9] J. T. Wang, D. S. Wang, C. Chen, O. Nashima, T. Kanomata, H. Mizuseki, and Y. Kawazoe, Appl. Phys. Lett. 89, 262504 (2006)

[10] N. T. Trung, L. Zhang, L. Caron, K. H. J. Buschow, and E. Bruck, Appl. Phys. Lett. 96, $172504(2010)$

[11] N. T. Trung, V. Biharie, L. Zhang, L. Caron, K. H. J. Buschow and E. Bruck, Appl. Phys. Lett. 96, 162507 (2010)

[12] E. K. Liu, W. Zhu, L. Feng, J. L. Chen, W. H. Wang, G. H. Wu, H. Y. Liu, F. B. Meng, H. Z. Luo, Y. X. Li , Europhys. Lett. 91, 17003 (2010)

[13] L. Caron, N. T. Trung and E. Bruck, Phys. Rev. B 84, 020414(R) (2011)

[14] S. Niziol, R. Zach, J. P. Senateur and J. Beille, J. Magn. Magn. Mater. 79, 333 (1989)

[15] V. Johnson, Inorg. Chem. 14, 1117 (1975)

[16] P. E. Markin, N. V. Mushnikov, V. I. Khrabrov and M. A. Korotin, The Physics of metals and metallography, 106, 5 (2008)

[17] W. Zhang, O. Tegus, Y. Wu, Yirgeltu, H. Yan and S. Lin, J. Mater. Sci. Technol. 25, 781 (2009)

[18] L. F. Bao, F. X. Hu, R. R. Wu, J. Wang, L. Chen, J. R. Sun, B. G. Shen, L. Li, B. Zhang and X. X. Zhang, J. Phys. D: Appl. Phys. 47, 055003 (2014)

[19] X. Si, Y. Liu, X. Lu, W. Wang, W. Lei, J. Lin, T. Zhou, and Y. Xu, Journal of Applied Physics 119, 215104 (2016)

[20] K. Koyama, M. Sakai, T. Kanomata, and K. Watanabe, Jpn. J. Appl. Phys., Part 1 43, 8036 (2004)

[21] S. Yuce, N. M. Bruno, B. Emre, and I. Karaman, Journal of Applied Physics 119, 133901 (2016) 
[22] T. Samanta, I. Dubenko, A. Quetz, S. Stadler, and N. Ali, Journal of Applied Physics 113, 17A922 (2013)

[23] T. Samanta, I. Dubenko, A. Quetz, S. Stadler, and N. Ali, Applied Physics Letters 101, 242405 (2012)

[24] L. Vegard, Z. Phys., 517 (1921)

[25] W. B. Pearson, The Crystal Chemistry and Physics of Metals and Alloys New York Wileyinterscience (1972)

[26] R. Jha, S. K. Singh, A. Kumar, V. P. S. Awana, J. Magn. Magn. Mater. 324, 2849 (2012)

[27] A. Aryal, A. Quetz, S. Pandey, T. Samanta, I. Dubenko, D. Mazumdar, S. Stadler and N. Ali, J. Appl. Phys. 119, 043905 (2016)

[28] K. A. Gschneidner, Jr. and V .K. Pecharsky "Magnetocaloric materials," Ann. Rev. Mater. Sci., 30, 387 (2000).

\section{List of Tables}

Table 1: Lattice parameters and unit cell volumes of hexagonal phase of $\mathrm{Mn}_{1-\mathrm{x}} \mathrm{Al}_{\mathrm{x}} \mathrm{CoGe}$ at room temperature.

\begin{tabular}{|c|c|c|c|}
\hline Concentration $(\mathbf{x})$ & $\mathbf{a}(\mathbf{\AA})$ & $\mathbf{c}(\mathbf{\AA})$ & Volume $\left(\AA^{\mathbf{3}}\right)$ \\
\hline 0.00 & $4.089(1)$ & $5.312(2)$ & $76.91(6)$ \\
\hline 0.01 & $4.094(1)$ & $5.325(1)$ & $77.32(3)$ \\
\hline 0.02 & $4.0954(6)$ & $5.3268(9)$ & $77.37(2)$ \\
\hline 0.03 & $4.0860(5)$ & $5.3146(7)$ & $76.84(1)$ \\
\hline 0.05 & $4.0774(5)$ & $5.2981(7)$ & $76.28(1)$ \\
\hline
\end{tabular}


Table 2: Type of phase transition, values of phase transition temperatures, maximum entropy change, RCP, L, and thermal hysteresis $(\Delta \mathrm{T})_{\text {hyst }}$ obtained from magnetization and DSC measurements for $\mathrm{Mn}_{1-\mathrm{x}} \mathrm{Al}_{\mathrm{x}} \mathrm{CoGe}$ compounds. All of the values tabulated below correspond to the heating cycles.

\begin{tabular}{|c|c|c|c|c|c|c|c|c|c|c|}
\hline \multirow[b]{2}{*}{$\mathbf{x}$} & \multirow{2}{*}{$\begin{array}{l}\text { Type of phase } \\
\text { transition }\end{array}$} & \multicolumn{5}{|c|}{ Magnetization measurement } & \multicolumn{4}{|c|}{ DSC measurement } \\
\hline & & $\mathbf{T}_{\mathbf{C}}(\mathbf{K})$ & $\mathbf{T}_{\mathbf{M}}(\mathbf{K})$ & $\begin{array}{c}-\Delta \mathbf{S}_{\mathrm{M}}(\mathrm{J} / \mathbf{k g ~ K}) \\
\Delta \mathrm{H}=\mathbf{5 T}\end{array}$ & $\begin{array}{c}\mathrm{RCP}(\mathrm{J} / \mathrm{Kg}) \\
\Delta \mathrm{H}=5 \mathrm{~T}\end{array}$ & $(\Delta \mathbf{T})_{\text {hyst }}(\mathbf{K})$ & $\mathbf{T}_{\mathbf{M}}(\mathbf{K})$ & $\mathbf{L}(\mathbf{J} / \mathbf{g})$ & $-\Delta \mathbf{S}_{\mathrm{T}}(\mathrm{J} / \mathrm{kg} \mathrm{K})$ & $(\Delta \mathbf{T})_{\text {hyst }}(\mathbf{K})$ \\
\hline $0.00 *$ & FM-PM & 345 & 650 & & & & & & & \\
\hline 0.00 & MST FM-PM & 313 & 313 & 18 & 250 & 10 & 313 & 7.74 & 25 & 16 \\
\hline 0.01 & MST FM-PM & 286 & 286 & 12 & 303 & 7 & 297 & 10.63 & 36 & 17 \\
\hline \multirow{2}{*}{0.02} & \multirow{2}{*}{ structurally driven FOT } & \multirow{2}{*}{281} & \multirow{2}{*}{220} & $7\left(\mathrm{~T}_{\mathrm{M}}\right)$ & $182\left(\mathrm{~T}_{\mathrm{M}}\right)$ & 7 & 214 & 1.73 & 8 & 21 \\
\hline & & & & $3\left(\mathrm{~T}_{\mathrm{C}}\right)$ & $217\left(\mathrm{~T}_{\mathrm{C}}\right)$ & & & & & \\
\hline 0.03 & SOT FM-PM & 281 & & 3.5 & 252 & & & & & \\
\hline 0.05 & SOT FM-PM & 281 & & 3.2 & 259 & & & & & \\
\hline
\end{tabular}

* Ref. [8]

\section{Figure Captions:}

Figure 1. a) Room temperature XRD patterns of $\mathrm{Mn}_{1-\mathrm{x}} \mathrm{Al}_{\mathrm{x}} \mathrm{CoGe}$ compounds with $0 \leq \mathrm{x} \leq 0.05$.

For $\mathrm{x}=0$, the orthorhombic peaks are indexed. For $\mathrm{x}>0$, the hexagonal peaks are indexed. The peaks with symbol " $\beta$ " are from the $\mathrm{K}_{\beta}$ wavelength. (b), and (c) show the Rietveld refinements of the XRD patterns of the compounds with $\mathrm{x}=0.01$ and $\mathrm{x}=0.02$ for hexagonal phase.

Figure 2. a) The temperature dependence of the magnetization $\mathrm{M}(\mathrm{T})$ for $\mathrm{Mn}_{1-\mathrm{x}} \mathrm{Al}_{\mathrm{x}} \mathrm{CoGe}$ with $0 \leq$ $\mathrm{x} \leq 0.05$ on heating and cooling in an applied field of 100 Oe. The solid and open symbols represent heating and cooling cycles, respectively. Inset: Field dependence of the magnetization 
$\mathrm{M}(\mathrm{H})$ at $\mathrm{T}=5 \mathrm{~K}$. b) DSC heat flow curves as a function of temperature. The arrows indicate the heating and cooling cycles.

Figure 3. Isothermal magnetization $\mathrm{M}(\mathrm{H})$ curves for $\mathrm{Mn}_{1-\mathrm{x}} \mathrm{Al}_{\mathrm{x}} \mathrm{CoGe}$ compounds with $\mathrm{x}=0.00$ and 0.01 .

Figure 4. Magnetic entropy changes $\left(-\Delta \mathrm{S}_{\mathrm{M}}\right)$ as a function of temperature for $\mathrm{Mn}_{1-\mathrm{x}} \mathrm{Al}_{\mathrm{x}} \mathrm{CoGe}$ compounds with a magnetic field change $\Delta \mathrm{H}=5 \mathrm{~T}$.

Figure 5. Concentration dependent phase diagram of $\mathrm{Mn}_{1-\mathrm{x}} \mathrm{Al}_{\mathrm{x}} \mathrm{CoGe}$. 

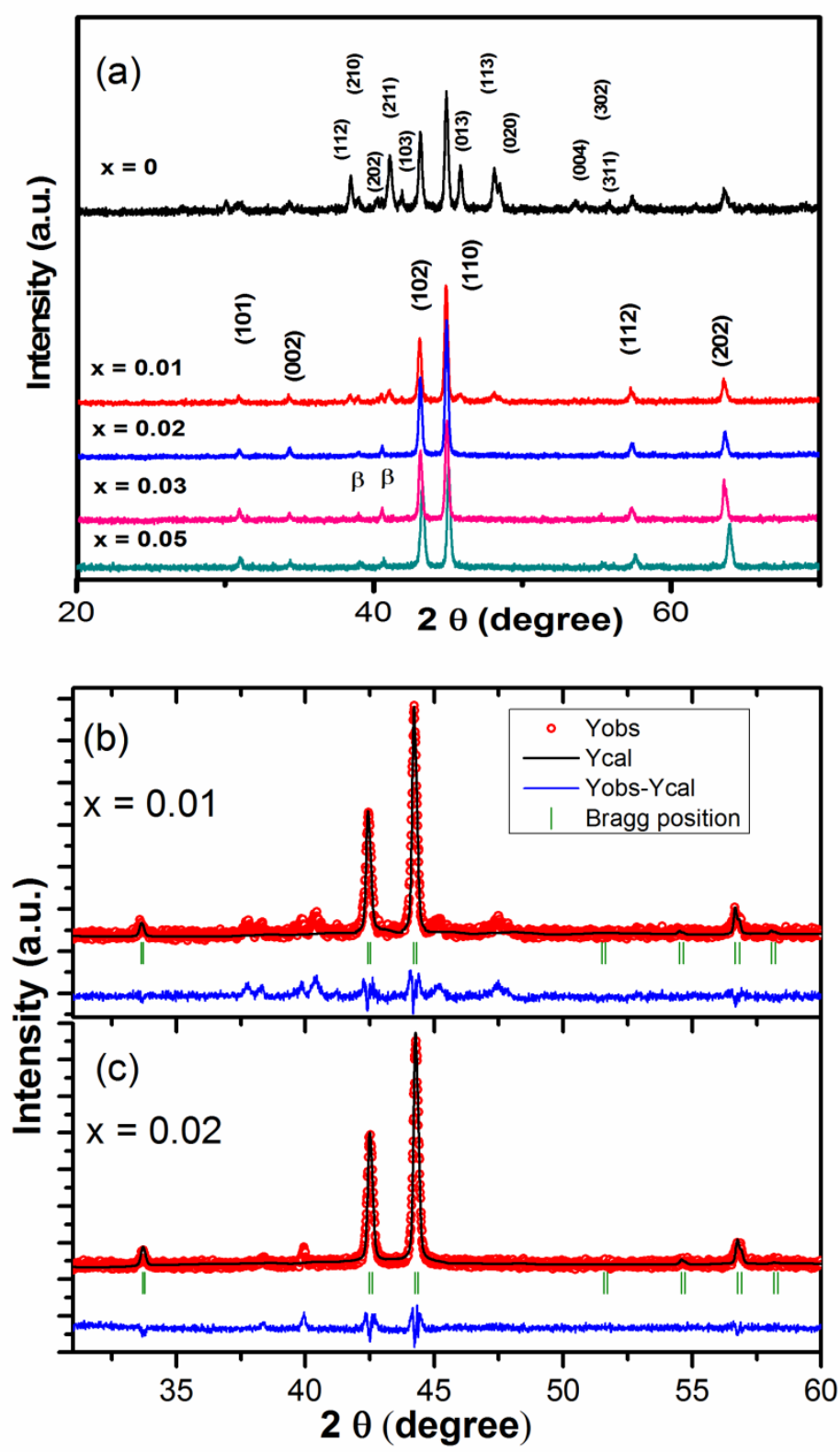

Figure 1. a) Room temperature XRD patterns of $\mathrm{Mn}_{1-\mathrm{x}} \mathrm{Al}_{\mathrm{x}} \mathrm{CoGe}$ compounds with $0 \leq \mathrm{x} \leq 0.05$. For $\mathrm{x}=0$, the orthorhombic peaks are indexed. For $\mathrm{x}>0$, the hexagonal peaks are indexed. The peaks with symbol " $\beta$ " are from the $\mathrm{K}_{\beta}$ wavelength. (b), and (c) show the Rietveld refinements of the XRD patterns of the compounds with $\mathrm{x}=0.01$ and $\mathrm{x}=0.02$ for hexagonal phase. 

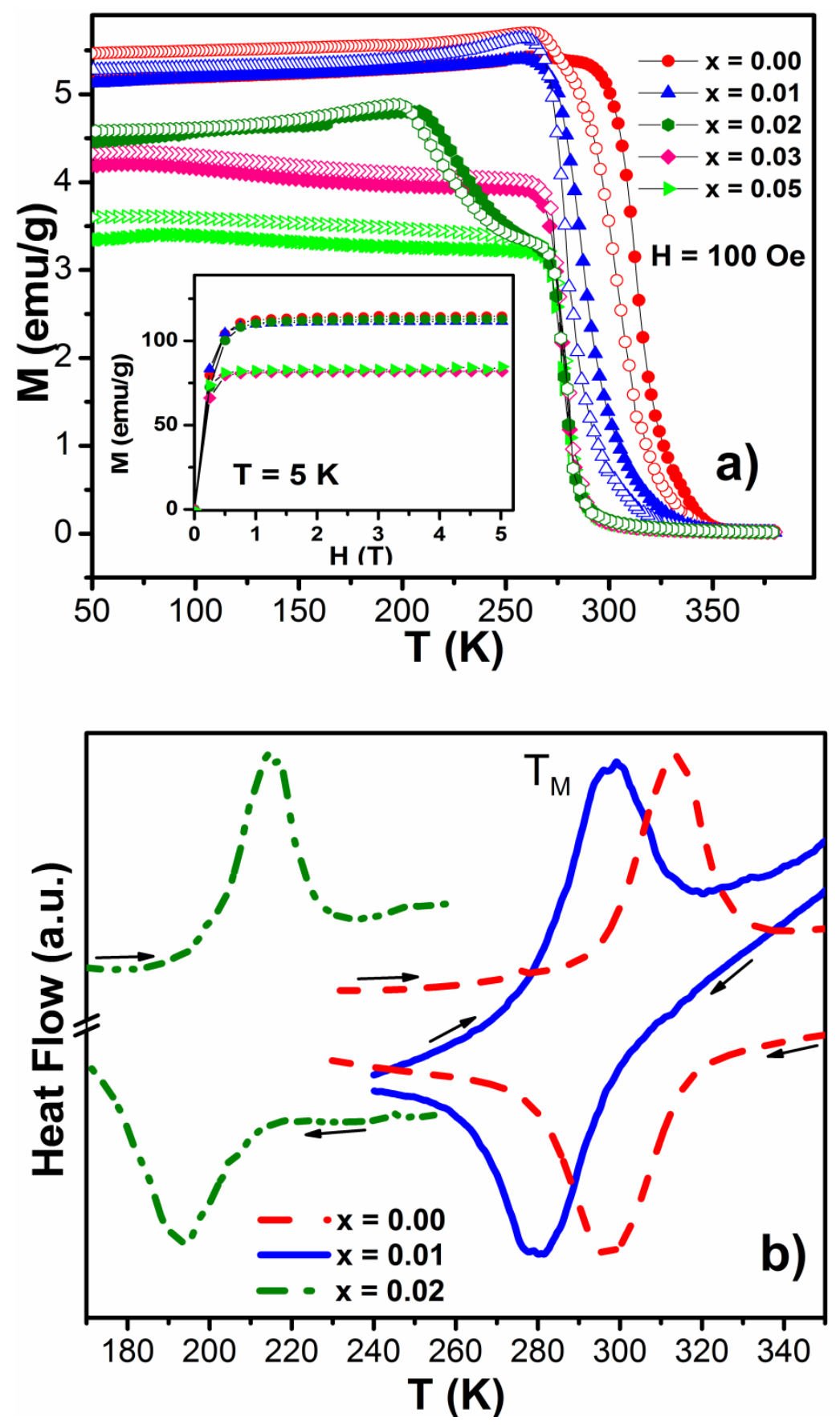

Figure 2. a) The temperature dependence of the magnetization $\mathrm{M}(\mathrm{T})$ for $\mathrm{Mn}_{1-\mathrm{x}} \mathrm{Al}_{\mathrm{x}} \mathrm{CoGe}$ with $0 \leq$ $\mathrm{x} \leq 0.05$ on heating and cooling in an applied field of 100 Oe. The solid and open symbols represent heating and cooling cycles, respectively. Inset: Field dependence of the magnetization $\mathrm{M}(\mathrm{H})$ at $\mathrm{T}=5 \mathrm{~K}$. b) DSC heat flow curves as a function of temperature. The arrows indicate the heating and cooling cycles. 

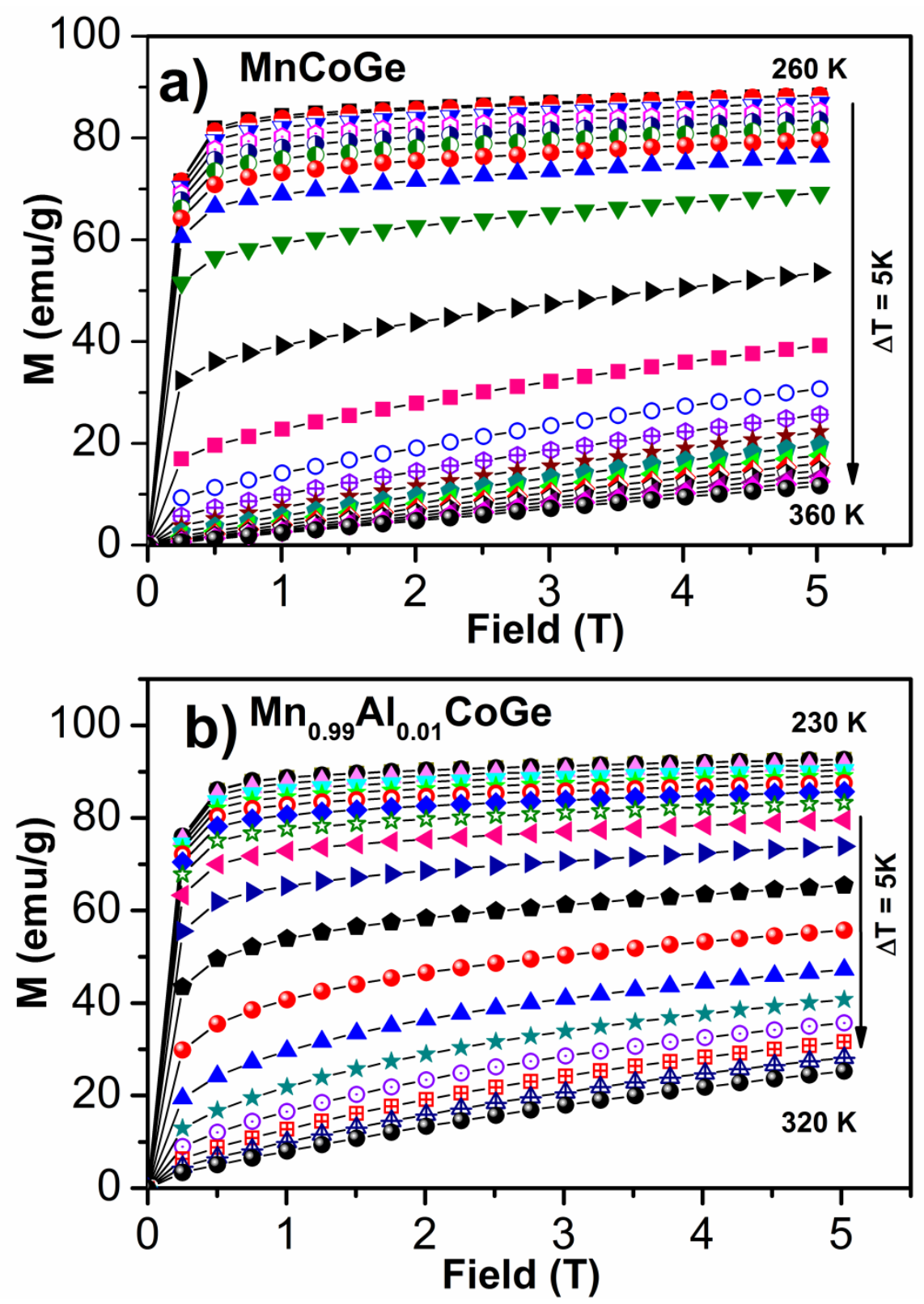

Figure 3. Isothermal magnetization $\mathrm{M}(\mathrm{H})$ curves for $\mathrm{Mn}_{1-\mathrm{x}} \mathrm{Al}_{\mathrm{x}} \mathrm{CoGe}$ compounds with $\mathrm{x}=0.00$ and 0.01 . 

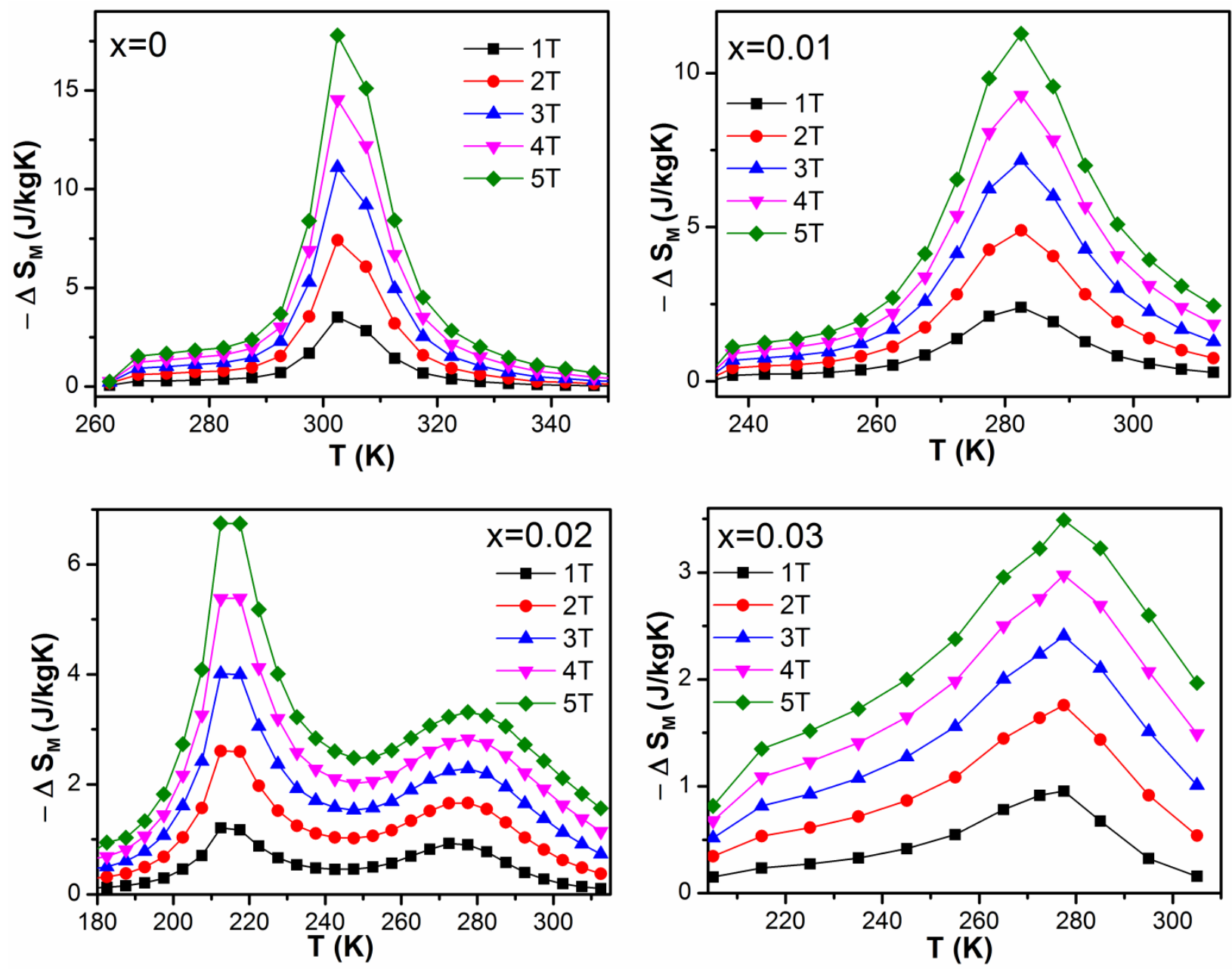

Figure 4. Magnetic entropy changes $\left(-\Delta \mathrm{S}_{\mathrm{M}}\right)$ as a function of temperature for $\mathrm{Mn}_{1-\mathrm{x}} \mathrm{Al}_{\mathrm{x}} \mathrm{CoGe}$ compounds with a magnetic field change $\Delta \mathrm{H}=5 \mathrm{~T}$. 


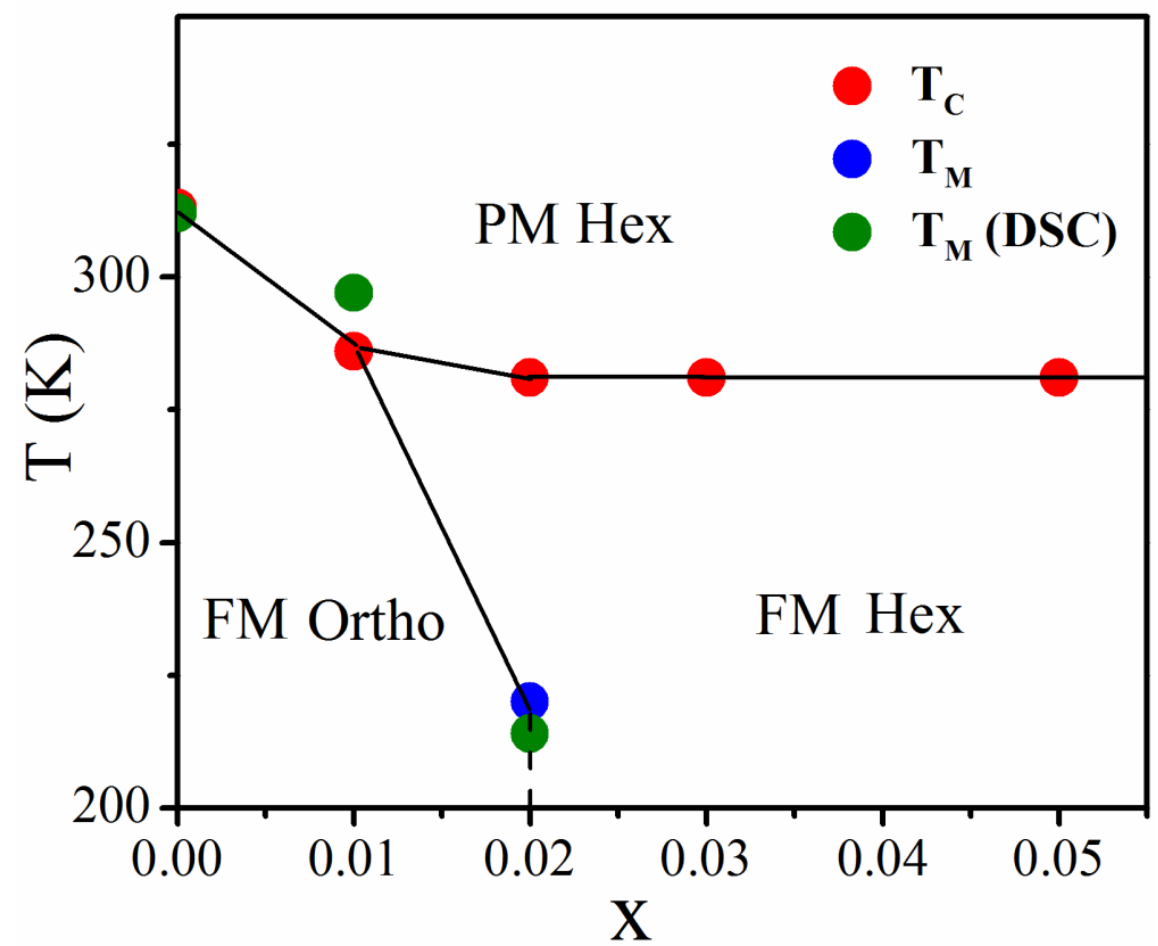

Figure 5. Concentration dependent phase diagram of $\mathrm{Mn}_{1-\mathrm{x}} \mathrm{Al}_{\mathrm{x}} \mathrm{CoGe}$. 